\title{
ESTIMATION OF ORTHOMETRIC HEIGHTS USING MODERN GPS SATELLITE-BASED POSITIONING DIFFERENT TECHNIQUES AND APPLICATIONS
}

\author{
El Shonuy A. F. \\ King AbdulAziz University, Faculty of environment Design, Jeddah, Saudi Arabia, \\ Assistant Professor, Survey Research Institute, National Water Research Center, Egypt, \\ E-mail: elshoney2003@yahoo.com
}

\begin{abstract}
One of the most interesting and challenging tasks in several fields and applications of geodetic surveying is obtaining orthometric or geoid heights. Determination of orthometric heights using traditional methods such as levelling works with different orders and standards is difficult and hard due to its long time, high cost, and big efforts but it is considered as the most accurate technique in determining orthometric heights. With the wide spread development of Global Positioning System and its different techniques and applications in the last periods, It was important to study the ability of using some of its applications instead of levelling works, and to investigate the accuracy obtained from each one of these techniques.
\end{abstract}

So the objective of this research is to study the use of several modern GPS satellite techniques and applications, such as local and global geoid models and precise point positioning, for determining orthometric heights, and also to evaluate the effect of using these techniques by comparing their results with that obtained from surveying levelling. The study area is located in Egypt and divided into two separated zones along the Mediterranean and Red Sea coastal lines. These areas are particularly important in order to assess the impacts of climate change and global warming using different suitable defense strategies. It has been found that local geoid model technique gives the best results comparing with the other techniques. It is recommended that a precise local geoid for all Egypt zone area should be created by co-operation of all interested organizations in this field.

Keywords: orthometric heights - global geopotential models - geoid surface modeling - Precise Point Positioning (PPP).

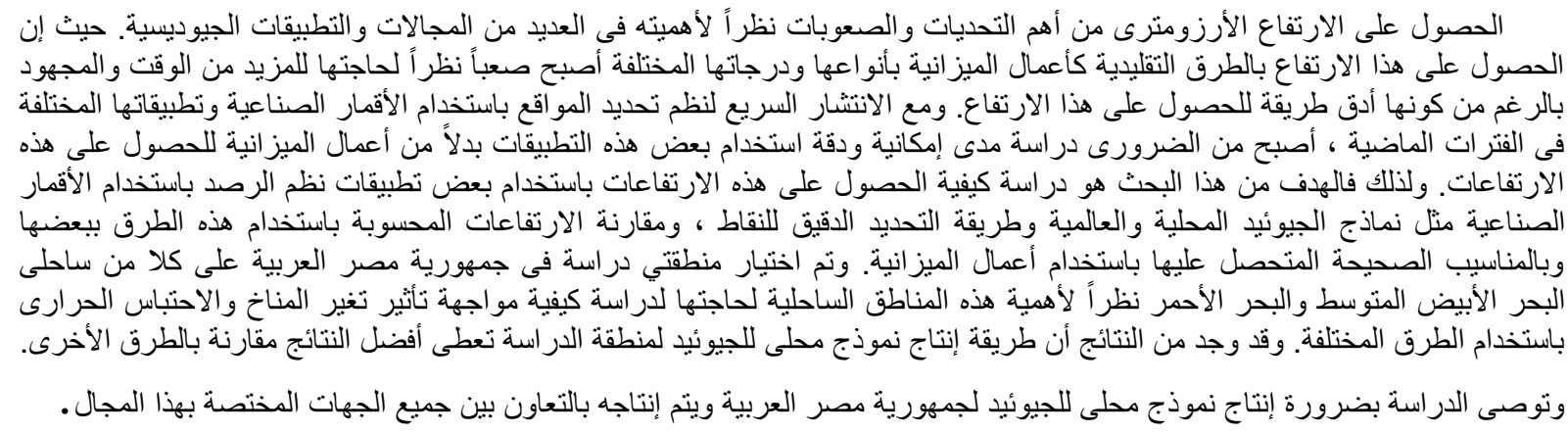

\section{INTRODUCTION}

The rapid growth of satellite positioning and its applications during the last few decades with its high accuracy and simplicity has opened the way to be used in different fields of surveying and geodetic applications. One of these fields is obtaining the geoid or orthometric height, which is defined as height related to Mean Sea Level (M.S.L.), due to its importance in different of surveying projects and works. Using classical method of levelling process is the most accurate method although it also needs long time and high cost. This long time and high cost is also increased in area with the shortage of known benchmarks, which causes difficulty due to performing very long leveling routes along these areas. So it is important to study alternative methods for obtaining orthometric heights using these modern satellite techniques and its recent development during the last periods.

This research including the study of several techniques of obtaining orthometric heights using Satellite Systems and applications such as precise 
point positioning service, Global Geopotential models and local geoid model creation. Each of these methods have been investigated, discussed, and also compared with height obtained from classical levelling operations to enable us to accurate evaluate the ability and accuracy of using each of these methods. The data used in this research is located along Egyptian Coastal Zones at Mediterranean Sea and Red Sea Coasts.

Several studies concerning obtaining orthometric heights from satellite applications had been performed before for different locations to investigate achieved accuracy of these methods. For example (Dawod G. et al., 2010) had investigated the accuracy of using Global Geopotential models for obtaining orthometric heights and they found that EGM2008 can play an essential role in integrated GPS surveys where the orthometric heights can be obtained without any additional costs, and also (Al Ghamdi K., and Dawod G., 2013) found that the EGM2008 model is the most precise GGM within Makkah metropolitan area, with an overall accuracy level about \pm 0.16 meter. While the study of obtaining this orthometric heights using local geoid models were investigated by (El-Shouny A. and Yakoub N., 2015) to study the efficiency and accuracy of using this technique. The use of PPP techniques were also analyzed by (Luo, X. et al., 2015) and proved the ability of using ppp technique in orthometric heights determination.

\section{METHODS OF OBTAINING ORTHOMETRIC HEIGHT BY USING GPS TECHNIQUES}

Satellite-based techniques including GPS measures three dimensional coordinates latitude, longitude, and ellipsoid height which refers to ellipsoidal surface, but many surveying projects and applications interested in orthometric height or height refers to geoid surface. The possibility of using modern satellite techniques and applications for obtaining orthometric height should be investigated and checked to determine the accuracy of each of these techniques in order to select the optimum one may be used instead of levelling according to the required accuracy and specifications of works. The following subsections give a brief explanation of the studied techniques in this research:

\subsection{USING (EGM2008) GLOBAL GEOPOTENTIAL MODEL}

GPS One of the most popular used techniques in researches in the last few period for converting ellipsoid height to orthometric height is Global Geopotential Models (GGMs). As known, there are several models of GGMs used all over the world to estimate geoidal undulation. GGMs comprises a set of spherical harmonic coefficients that describe the long wavelength characteristics of the earth gravity field. These are computed from the analysis of artificial earth - satellite orbits, and higher resolution combined GGMs also include terrestrial gravity terrain and satellite alimetry data. In this study we choose most recent Earth Geopotential Model (EGM 2008) to obtain orthometric height from GPS derived height.

EGM2008 is a spherical harmonic model of the Earth's gravitational potential, developed by a least squares combination of the ITG-GRACE03S gravitational model and its associated error covariance matrix, with the gravitational information obtained from a global set of area-mean free-air gravity anomalies defined on a 5 arc-minute equiangular grid. This grid was formed by merging terrestrial, altimetry-derived, and airborne gravity data. Over areas where only lower resolution gravity data were available, their spectral content was supplemented with gravitational information implied by the topography. EGM2008 is complete to degree and order 2159, and contains additional coefficients up to degree 2190 and order 2159 (Dawod G. et al., 2010).

In this method, we should use Static GPS observing Technique with at least one or more instrument installed on control points as a base to be able to perform processing for observations and also adjustment process for the data using minimum or over constraints solution to check the quality of the data, and to determine accurate points coordinates including ellipsoid height, after performing adjustment process and achieving the required accuracy of works. (EGM2008) were used to transform ellipsoid height to orthometric height.

\subsection{CREATION OF LOCAL GEOID SURFACE MODEL FOR THE STUDY AREA}

This method depends on creation of a local geoid model for the work area using one of the different surface Fitting methods. The creation of this local geoid model may be performed using gravity data (called as gravimetric method) or GPS/Levelling data (called as geometric method) and this geometric method is the most popular used one due its simplicity and also due to the lack of gravity data. The fundamental theory of this method is based on determining adjusted coordinates including ellipsoid height using GPS observation and also the orthometric height of some reference points using levelling with high quality and precision. It is important before the creation of this model to decide the number of these reference points and their locations at the study area. These points number must 
not less than (3) points and they may be more depends on the work area and also the geoid features in this area where the greater change in geoid features, the more number of points. And the selection of these points locations along the study area should be distributed homogenously all over the area. After determining field data containing ellipsoid and orthometric height, geoid undulation can be calculated using equation (1) (Al Ghamdi K., and Dawod G., 2013). The relation between ellipsoidal height, orthometric height and geoid undulation is shown in Figure (1).

$$
\boldsymbol{N}=\boldsymbol{h}-\boldsymbol{H}
$$

where:

$\mathrm{h}$ : ellipsoidal height,

$\mathrm{H}$ : orthometric height, and

$\mathrm{N}$ : geoid undulation.

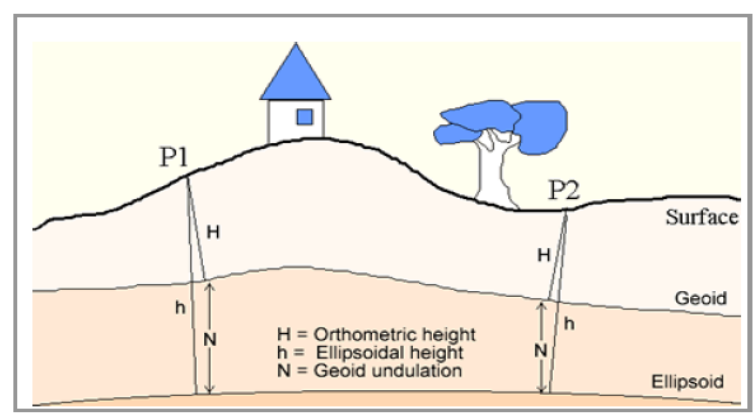

Figure (1): Relation between ellipsoidal height, orthometric height and geoid undulation (geoid height) (http:// kartoweb. itc. nl/ geometrics/, accessed August 2000)

After calculating geoid undulation, one of the geoid interpolation surface modeling techniques such as regression, Kriging, IDW should be used to create geoid model along the study area. These geoid surface modeling techniques take into consideration the effect of non-linear geoid model of the geoid surface along the study area. In this study, we used krigging method to create the local geoid model because it has proven useful and popular in many fields of geodesy. For more information of surface modeling methods see (El-Shouny A. and Yakoub N., 2015).

\subsection{BY COMPUTING GPS BASELINE DIFFERENCE IN ELEVATIONS}

This method depends on performing GPS static observations and calculating baselines difference in heights $(\Delta \mathrm{h})$, each baseline begins with benchmark with known orthometric height and ends with one of the points which needs to calculate their orthometric height. This methodology does not require any calculation of local or global geoid models. Indeed, the variation of the geoid undulation between two control points may be ignored if the distance is small enough depending on the required accuracy. And orthometric height of any selected points is equal to orthometric height of its base GPS point adding calculated $\Delta h$ value of their coonected baseline.

To increase the accuracy of this method, we should minimize the length of each baseline to decrease the probability of errors and, also if possible we can use more than one benchmark as a base according to its availability along the work area. The time of observation should be enough to be able to perform the processing and adjustment processes with the required accuracy. And it is better if we use precise ephemeris instead of Broadcast ephemeris to increase accuracy of the results. The disadvantage of this method is the assumption that no difference in geoid undulation between the used benchmark and others points, and this isn't right. In order to decrease the effect of this, we should decrease the baselines lengths as much as we can depending on the availability of benchmarks around the study area, and also geoid undulation criteria along the study area.

\subsection{USING GPS PRECISE POINT POSITIONING TECHNIQUE (PPP)}

Differential Static GPS Technique used in several surveying applications depends on the measurements accuracy of reference receiver or corrections from a network. In the end of the last century, a standalone GPS point positioning technique has been developed to be used in geodetic applications. This technique is known as Precise Point Positioning (PPP). PPP using GPS measurements achieves accuracy of Static and Kinematic Stations at the millimeter to decimeter levels, respectively (Zumberge et al., 1997 - Bisnath aw gao, 2009). So it has been utilized in a wide range of applications, such as aerial triangulation, crustal deformation monitoring, hydrographic applications, and digital elevation model evaluation. (Mohamed $\mathrm{H}$. F., 2015).

The PPP processing strategy fully exploits the double - frequency phase and the code observations to remove any first order ionosphere bias. Additionally, the use of precise international Global Navigation Satellite System (GNSS) service (IGS) products and the modeling of all biases on the centimeter level (e.g. site displacement effects, relatively, phase, wind up, troposphere delay) is mandatory. However, for the coordinates of the highest precision, the troposphere parameters, receiver - clock offset parameters, and the ambiguity parameter must also be estimated (Kouba J., 2009 Qiuying Guo, 2015). In PPP, the following ionosphere - free combined observations are 
generally used to form the observation equations (Andrew W. Sutter \& Alan G. Evans, 2004):

$$
\begin{aligned}
& \ell_{P}=\rho+C(d t-d T)+M z t d+\varepsilon P \\
& \ell_{\Phi}=\rho+C(d t-d T)+M z t d+N \lambda+\varepsilon \Phi
\end{aligned}
$$

where:

$\ell_{P}:$ is the ionosphere-free combination of L1 and L2 pseudo ranges $\left(2.54 \mathrm{P}_{1}-1.54 \mathrm{P}_{2}\right)$,

$\ell_{\Phi}$ : is the ionosphere-free combination of L1 and L2 carrier-phases $\left(2.54 \Phi_{1}-1.54 \Phi_{2}\right)$,

$d t$ : is the station clock offset from GPS time,

$d T:$ is the satellite clock offset from GPS time,

$C:$ is the vacuum speed of light,

$\lambda$ :is the carrier, or carrier-combination, wavelength,

$N$ : is the ambiguity of the carrier-phase ionospherefree combination,

$\mathrm{M}$ : is function to map tropospheric from slant to zenith,

$z t d$ : is the signal tropospheric zenith total delay due to the neutral-atmosphere, wavelength, ionospherefree combination.

$\varepsilon P, \varepsilon \Phi:$ are the relevant measurement noise components.

\section{CASE STUDY}

\subsection{STUDY AREA AND AVAILABLE DATA}

The study area is located in Egypt and divided into two separated zones along the Mediterranean and Red Sea Coastal Lines respectively due to the importance of these areas because of the impact of climate change and global warming and its defense strategies. First zone area is located along Mediterranean Sea at Northern of Egypt starts from Al Alamin city East and extends to $\mathrm{Al}$ Arish governorate West, with a length of about $(650) \mathrm{km}$. While second zone area of Red Sea Coasts at Eastern of Egypt is located along Suez Gulf two sides from Suez city at North and extended to South at Ras Ghareb city at the East side, and to Sharm El-Sheikh city at the West side, also extended along Aqaba Gulf from Sharm El-Sheikh at South to Taba city at North of the Aqaba Gulf with a total length of about (650) $\mathrm{km}$. Figure (2) shows the study area and available data distribution along this study area. The majority of this dataset comes from a research project carried out by the Survey Research Institute (SRI) in cooperation with Coastal Protection Agency (Survey Research Institute Technical Report, June 2016). The following subsections describes the field works and used techniques and results are shown.

\subsection{FIELD WORKS AND OBSERVATIONS}

a) Planning and Monumentation of Permanent Reference Control Points

As known planning is one of the most important parts of any engineering projects to ensure reaching of the required accuracy of works through determination of the best locations for the establishment of control points. Also to locate positions and case of old benchmarks and control points which will be used during observations. In planning process, it is important to select instruments, observations plans, and best times, and the required accuracy for observation process. After finishing this planning process, the control points have been established in the selected locations. The distribution of these (96) control points along the study area is shown in Figure (2).

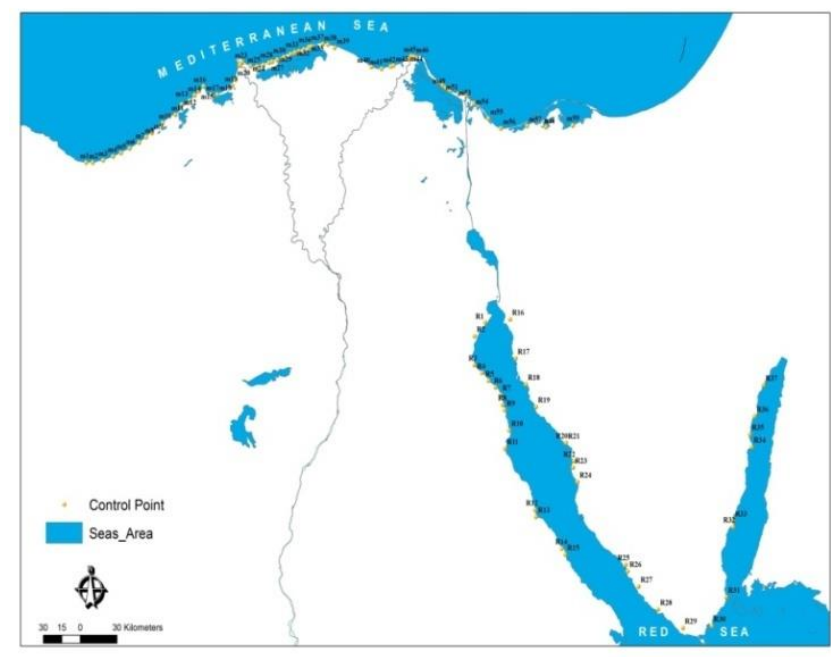

Figure (2): The study area and available data

The construction of each point consists of a concrete prism with $(40 \mathrm{~cm} \times 40 \mathrm{~cm})$ for the upper dimensions and $(60 \mathrm{~cm} \times 60 \mathrm{~cm})$ for the lower dimensions and one meter height with about $(50) \mathrm{cm}$ underground. A circular steel cylinder is mounted at the top of the concrete prism welded to a $10 \mathrm{~cm}$ steel bar fixed inside the concrete prism. Figure (3) shows samples of these control points view.

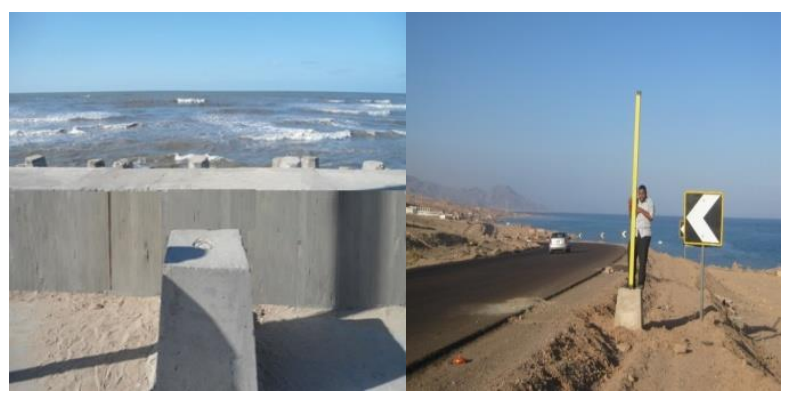

Figure (3): Samples of control points view.

\section{b) Levelling Process Observations}

It was important to obtain orthometric heights of all reference points with high accuracy to have the ability of evaluation the performance of each one of the used methods in determining of these points 
orthometric heights. To do so, precise levelling have been performed between these points with precise level to achieve first order levelling standards. All points have been connected in a closed levelling circuit begins from Egyptian Survey Authority (ESA) first order benchmark and ends with the same benchmark or with another first order benchmark to calculate misclosure and obtained final orthometric height of all these points. Two types of ESA benchmarks were used in levelling works, ground and wall as shown in Figure (4). Precise levelling process have been performed using Wild N3 level, shown in Figure (4), with micrometer and invar staff.

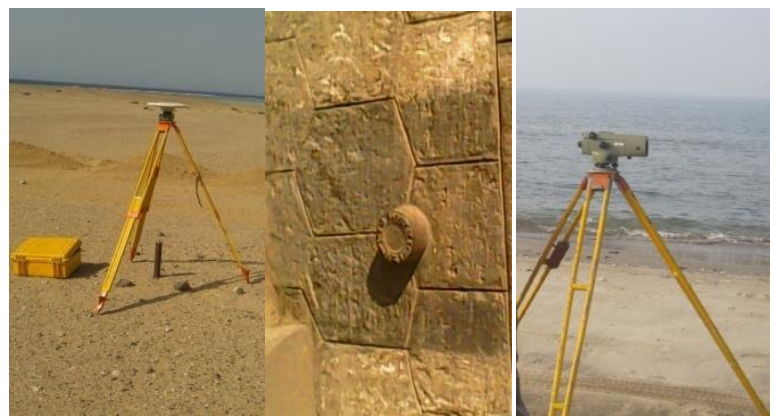

Figure (4): Types of ESA benchmarks and used level instrument

\section{c) GPS Observations}

All of these reference points have been observed using GPS dual frequency instruments. In order to obtain the three dimensional coordinates including ellipsoid heights. Almanac was checked before observations process to select the best periods of measurements collection and duration of observing session for each baselines. The GPS measurements were divided into two separate sections, each one were observed as an independent network taking into consideration network design and strength standards and conditions. Observations process were performed using (5) Trimble 5700 instruments, shown in Figure (5), with several sequential sessions. Measurements were performed using network method where (2) instruments as a base and the other (3) instruments as a rover ones. Observations were performed using static observation technique with a suitable observation time. ESA first triangulation points, as shown in Figure (5), were used to increase the accuracy of reference points coordinates. ESA benchmarks used in levelling processes were included in GPS observations to enable us to perform different used techniques of obtaining orthometric height using GPS techniques and applications. Figure (6) shows the figure of the observed network (2) along Red Sea Coast zone area all over Sinai governorate. The processing and adjustment of these networks have been performed using Trimble
Business Center (TBC) in order to determine all points coordinates, latitude, longitude, and ellipsoid height, with high accuracy, while orthometric height may be obtained with the use of GPS observations using different techniques, as discussed before at section (2), these techniques methodology will illustrate at the following subsections:

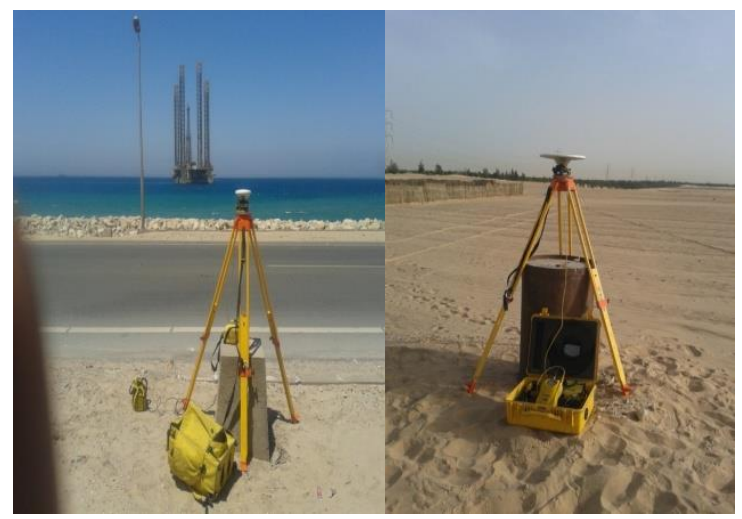

Figure (5): GPS instrument and ESA triangulation point

\section{Using GGMs Global Geopotential Models}

After finishing the processing and adjustment processes of GPS measurements, and determining three dimensional coordinates with the required accuracy. EGM 2008 Global Geopotential Geoid models, as discussed in subsection 2.1 , have been used to calculate orthometric heights of points along study area. EGM2008 calculate geoid undulation of each of points and then calculate the orthometric heights of these points using equation (1). Combined Tables (1) and (2) show results obtained from this model and also statistics of these results respectively.

\section{Using Local Geoid Surface Fitting Solutions}

(50) reference of the all available (96) points along the study area with homogenous distribution were selected to create a local geoid model, as indicated in subsection 2.2 using equation (1), all the area using both orthometric and ellipsoid height. To create this geoid model, and to calculate height with high precision, we used surface fitting method of krigging as one of most used surface fitting method. Results and statistics of this local geoid model are also shown in Tables (1) and (2).

\section{Using GPS Baseline Difference in Height}

In this method, it was important to perform high accurate differential GPS observations in static mode with necessary condition that the base point must be a first order benchmark with known orthometric height with high accuracy. During processing and adjustment operations, orthometric height of the 
rover is calculated using the value of orthometric height of base with adding calculated $\Delta h$ of their GPS baseline ignoring variation of the geoid undulation between the both points of baselines.

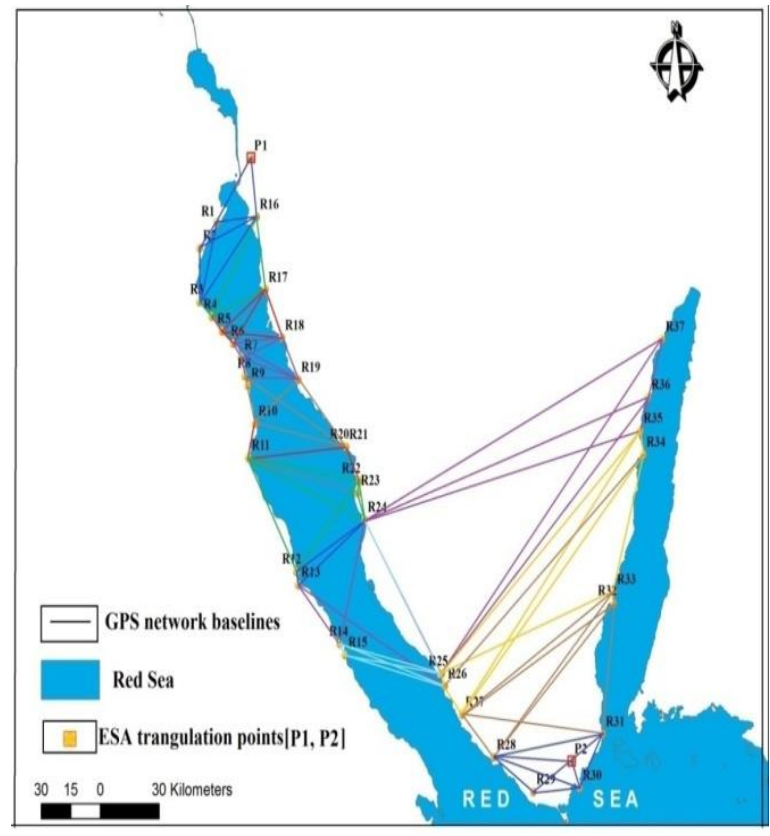

Figure (6): Network (2) design along Red Sea zone area

This method is simple and easy but it neglects the influence of non-linear of the geoid surface along each session of observations. To increase the accuracy of this method, it was necessary to use a lot of benchmarks with known orthometric height in order to decrease the baselines length between base and rover to decrease the error of neglecting difference of the geoid surface. Results of this method are shown in Tables (1) and (2).

\section{Using Precise Point Positioning (PPP) \\ Technique}

In this method, Precise Point Positioning (PPP) Technique was used to provide positions solutions with acceptable accuracy. PPP involves only a single GPS receiver and, therefore, no reference stations are needed in the vicinity of the user. Data have been submitted to Natural Resources Canada online GPS Processing Service, (GA, 2011) to be processed using IGS (International GNSS System) stations network and IGS product range. Data have been converted to Rinex form and submitted after (14) days of observations time to enable the service using precise ephemeris to increase the accuracy of obtained coordinates and heights. This Canadian Spatial Reference System (CSRS) Precise Point Positioning (PPP) tool allows the computation of higher accuracy positions of raw (GNSS) data, the GPS.H tool performs the conversion of ellipsoidal heights to orthometric heights. Results and statistics obtained from this method are shown in Tables (1) and (2).

Table (1): Differences in obtained orthometric heights from each of used techniques

\begin{tabular}{|c|c|c|c|c|}
\hline Point ID & $\begin{array}{l}\text { EGM } \\
2008\end{array}$ & $\begin{array}{l}\text { Local geoid } \\
\text { model }\end{array}$ & $\begin{array}{l}\text { Baselines } \\
\text { difference }\end{array}$ & PPP \\
\hline $\mathrm{m} 1$ & -0.100 & used in model & 0.237 & -0.225 \\
\hline $\mathrm{m} 2$ & -0.117 & 0.030 & 0.183 & $\begin{array}{l}-0.374 \\
\end{array}$ \\
\hline m3 & -0.224 & used in model & 0.067 & -0.606 \\
\hline m4 & -0.164 & 0.009 & 0.000 & $\begin{array}{c}-0.400 \\
\end{array}$ \\
\hline $\mathrm{m5}$ & -0.122 & used in model & $\begin{array}{c}-0.045 \\
\end{array}$ & $\begin{array}{c}-0.371 \\
\end{array}$ \\
\hline m6 & -0.034 & 0.020 & -0.088 & -0.551 \\
\hline m7 & -0.029 & used in model & -0.076 & $\begin{array}{l}-0.334 \\
\end{array}$ \\
\hline m8 & -0.071 & -0.111 & -0.065 & $\begin{array}{c}-0.507 \\
\end{array}$ \\
\hline m9 & 0.057 & used in model & -0.134 & -0.271 \\
\hline $\mathrm{m} 10$ & 0.339 & 0.444 & -0.059 & $\begin{array}{l}-0.283 \\
\end{array}$ \\
\hline $\mathrm{m} 11$ & -0.350 & used in model & 0.000 & -0.391 \\
\hline$\overline{\mathrm{m} 12}$ & -0.153 & 0.102 & 0.123 & $\begin{array}{c}-0.602 \\
\end{array}$ \\
\hline $\mathrm{m} 13$ & -0.236 & used in model & -0.121 & -0.522 \\
\hline$\overline{\mathrm{m} 14}$ & -0.287 & -0.020 & 0.303 & -0.475 \\
\hline m15 & -0.287 & "used in model & 0.391 & $\begin{array}{c}-0.568 \\
\end{array}$ \\
\hline$\overline{\mathrm{m} 16}$ & -0.285 & 0.019 & \begin{tabular}{c|}
-0.007 \\
\end{tabular} & 1.907 \\
\hline $\mathrm{m} 17$ & -0.373 & used in model & 0.017 & $\begin{array}{c}-0.705 \\
\end{array}$ \\
\hline $\mathrm{m} 18$ & -0.402 & -0.031 & 0.047 & $\begin{array}{c}-0.707 \\
\end{array}$ \\
\hline m19 & -0.478 & used in model & 0.310 & $\begin{array}{c}-0.083 \\
\end{array}$ \\
\hline $\mathrm{m} 20$ & -0.494 & -0.035 & 0.431 & $\begin{array}{c}-0.660 \\
\end{array}$ \\
\hline $\mathrm{m} 21$ & -0.504 & used in model & 0.843 & -0.817 \\
\hline $\mathrm{m} 22$ & -0.485 & 0.014 & -0.020 & $\begin{array}{c}-0.657 \\
\end{array}$ \\
\hline $\mathrm{m} 23$ & -0.467 & used in model & 0.825 & -0.885 \\
\hline$\overline{\mathrm{m} 24}$ & -0.584 & -0.029 & 0.863 & $\begin{array}{c}-0.764 \\
\end{array}$ \\
\hline $\mathrm{m} 25$ & -0.628 & "used in model & 0.756 & $\begin{array}{c}-0.904 \\
\end{array}$ \\
\hline $\mathrm{m} 26$ & -0.624 & -0.020 & 0.125 & $2-0.796$ \\
\hline $\mathrm{m} 27$ & -0.586 & used in model & 0.133 & -0.771 \\
\hline $\mathrm{m} 28$ & -0.582 & 0.021 & 0.141 & 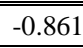 \\
\hline m29 & -0.630 & used in model & 0.148 & -0.822 \\
\hline $\mathrm{m} 30$ & -0.590 & 0.015 & 0.157 & $\begin{array}{l}-0.708 \\
\end{array}$ \\
\hline m31 & -0.583 & used in model & 0.165 & -0.201 \\
\hline $\mathrm{m} 32$ & -0.575 & 0.002 & 0.174 & -0.259 \\
\hline m33 & -0.554 & used in model & 0.182 & 0.116 \\
\hline $\mathrm{m} 34$ & -0.745 & -0.109 & -0.496 & 0.293 \\
\hline m35 & -0.742 & used in model & -0.397 & 0.171 \\
\hline $\mathrm{m} 36$ & -0.760 & -0.016 & -0.364 & 0.417 \\
\hline m37 & -0.723 & used in model & -0.200 & 1.263 \\
\hline $\mathrm{m} 38$ & -0.707 & 0.033 & -0.325 & -0.377 \\
\hline
\end{tabular}

Note: $\mathrm{m}^{*}$ : points along Mediterranean Sea Coast 
Table (1): Cont. Differences in obtained orthometric heights from each of used techniques

\begin{tabular}{|c|c|c|c|c|}
\hline Point ID & $\begin{array}{l}\text { EGM } \\
2008\end{array}$ & $\begin{array}{l}\text { Local geoid } \\
\text { model }\end{array}$ & $\begin{array}{l}\text { Baselines } \\
\text { difference }\end{array}$ & PPP \\
\hline $\mathrm{m} 39$ & -0.703 & used in model & -0.412 & -1.021 \\
\hline $\mathrm{m} 40$ & -0.355 & used in model & -0.517 & -0.965 \\
\hline $\mathrm{m} 41$ & -0.365 & -0.070 & 0.000 & -0.672 \\
\hline $\mathrm{m} 42$ & -0.358 & used in model & -0.154 & -0.564 \\
\hline $\mathrm{m} 43$ & -0.375 & 0.001 & -0.124 & -0.202 \\
\hline $\mathrm{m} 44$ & -0.430 & used in model & 0.197 & -0.270 \\
\hline $\mathrm{m} 45$ & -0.433 & 0.039 & -0.213 & -0.807 \\
\hline $\mathrm{m} 46$ & -0.470 & used in model & 0.238 & -0.741 \\
\hline $\mathrm{m} 47$ & -0.562 & -0.046 & 0.354 & -0.564 \\
\hline $\mathrm{m} 48$ & -0.551 & used in model & 0.245 & -0.713 \\
\hline $\mathrm{m} 49$ & -0.498 & -0.018 & 0.230 & -0.774 \\
\hline $\mathrm{m} 50$ & -0.400 & used in model & 0.000 & -0.441 \\
\hline $\mathrm{m} 51$ & -0.424 & -0.026 & 0.114 & -0.493 \\
\hline $\mathrm{m} 52$ & -0.461 & used in model & 0.000 & -0.654 \\
\hline m53 & -0.345 & -0.007 & -0.012 & -0.605 \\
\hline $\mathrm{m} 54$ & -0.253 & used in model & -0.279 & -0.554 \\
\hline $\mathrm{m} 55$ & -0.250 & -0.134 & 0.012 & -0.551 \\
\hline $\mathrm{m} 56$ & -0.250 & used in model & -0.193 & -0.532 \\
\hline $\mathrm{m} 57$ & -0.033 & 0.255 & 0.167 & -0.320 \\
\hline $\mathrm{m} 58$ & -0.017 & 0.321 & 0.307 & -0.415 \\
\hline m59 & 0.028 & used in model & 0.041 & -0.572 \\
\hline $\mathrm{R} 1$ & 1.028 & used in model & 0.000 & -0.284 \\
\hline $\mathrm{R} 2$ & 0.987 & -0.306 & 0.066 & -0.601 \\
\hline $\mathrm{R} 3$ & 1.017 & used in model & 0.648 & -0.253 \\
\hline $\mathrm{R} 4$ & 0.906 & -0.061 & 0.495 & -0.206 \\
\hline $\mathrm{R} 5$ & 0.855 & used in model & 0.380 & -0.235 \\
\hline R6 & 0.728 & 0.000 & 0.190 & -0.368 \\
\hline $\mathrm{R} 7$ & 0.538 & used in model & 0.055 & -0.352 \\
\hline $\mathrm{R} 8$ & 0.348 & 0.053 & 0.097 & 0.102 \\
\hline $\mathrm{R} 9$ & 0.195 & used in model & 0.039 & 0.194 \\
\hline $\mathrm{R} 10$ & 0.184 & -0.018 & 0.112 & -0.390 \\
\hline $\mathrm{R} 11$ & -0.053 & used in model & 0.271 & -0.458 \\
\hline $\mathrm{R} 12$ & -0.613 & -0.232 & -0.696 & -1.856 \\
\hline $\mathrm{R} 13$ & -0.557 & used in model & -0.543 & -0.812 \\
\hline $\mathrm{R} 14$ & -0.636 & -0.028 & -0.828 & -0.805 \\
\hline $\mathrm{R} 15$ & -0.677 & used in model & -0.849 & -0.907 \\
\hline $\mathrm{R} 16$ & 0.781 & used in model & 0.062 & -0.426 \\
\hline $\mathrm{R} 17$ & 0.464 & -0.268 & -0.250 & -0.255 \\
\hline
\end{tabular}

Note: $\mathrm{R}$ : points along Red Sea Coast
Table (1): Cont. Differences in obtained orthometric heights from each of used techniques

\begin{tabular}{|c|c|c|c|c|}
\hline Point ID & $\begin{array}{l}\text { EGM } \\
2008\end{array}$ & $\begin{array}{l}\text { Local geoid } \\
\text { model }\end{array}$ & $\begin{array}{l}\text { Baselines } \\
\text { difference }\end{array}$ & PPP \\
\hline $\mathrm{R} 18$ & 0.058 & used in model & -0.084 & -0.743 \\
\hline R19 & -0.150 & -0.063 & 0.065 & -0.148 \\
\hline $\mathrm{R} 20$ & -0.274 & used in model & 0.485 & -0.890 \\
\hline $\mathrm{R} 21$ & -0.281 & -0.007 & 0.473 & -0.884 \\
\hline $\mathrm{R} 22$ & -0.375 & used in model & 0.313 & -0.757 \\
\hline $\mathrm{R} 23$ & -0.345 & -0.100 & 0.051 & -0.736 \\
\hline $\mathrm{R} 24$ & -0.375 & used in model & 0.042 & -0.506 \\
\hline $\mathrm{R} 25$ & -0.467 & 0.074 & -0.873 & -0.622 \\
\hline $\mathrm{R} 26$ & -0.564 & used in model & -0.890 & -0.685 \\
\hline $\mathrm{R} 27$ & -0.142 & used in model & -0.507 & -0.202 \\
\hline $\mathrm{R} 28$ & 0.035 & 0.187 & -0.079 & 0.183 \\
\hline $\mathrm{R} 29$ & 0.203 & used in model & -0.147 & 0.375 \\
\hline $\mathrm{R} 30$ & 0.753 & -0.454 & -0.811 & 0.973 \\
\hline $\mathrm{R} 31$ & 1.106 & used in model & -0.584 & 1.224 \\
\hline $\mathrm{R} 32$ & 1.720 & -0.233 & -0.424 & 1.771 \\
\hline R33 & 1.903 & used in model & -0.176 & 1.928 \\
\hline R34 & 1.427 & -0.457 & 0.115 & 1.407 \\
\hline $\mathrm{R} 35$ & 1.761 & used in model & 0.612 & 1.591 \\
\hline R36 & 1.391 & -0.255 & 0.593 & 1.221 \\
\hline R37 & 1.044 & used in model & 0.964 & 0.907 \\
\hline
\end{tabular}

Table (2): Statistics of results for each of used techniques ( in meter )

\begin{tabular}{|c||c||c||c||c|}
\hline Statistics & $\begin{array}{c}\text { EGM } \\
\mathbf{2 0 0 8}\end{array}$ & $\begin{array}{c}\text { Local } \\
\text { geoid } \\
\text { model }\end{array}$ & $\begin{array}{c}\text { Baselines } \\
\text { difference }\end{array}$ & PPP \\
\hline Maximum & 1.903 & 0.444 & 0.964 & 1.928 \\
\hline \hline Minimum & -0.760 & -0.457 & -0.890 & -1.856 \\
\hline \hline average & -0.088 & -0.033 & 0.027 & -0.294 \\
\hline \hline $\begin{array}{c}\text { standard } \\
\text { deviations }\end{array}$ & 0.622 & 0.163 & 0.381 & 0.684 \\
\hline
\end{tabular}




\section{RESULTS AND DISCUSSIONS}

The Table (1) shows the differences between the calculated orthometric heights from each techniques discussed before and orthometric heights obtained from precise levelling. While Table (2) shows the statistics of these results for each technique. As shown from Tables, for the study area, local geoid creation using krigging method gives the best results comparing with all other techniques, where orthometric heights difference ranges from $(0.444) \mathrm{m}$ to $(-0.457) \mathrm{m}$ with $(16.3) \mathrm{cm}$ standard deviations for all values. While baseline difference technique comes in the second place with difference ranges from $(0.964) \mathrm{m}$ to $(-0.890) \mathrm{m}$ with $(38.1) \mathrm{cm}$ standard deviations. Then EGM2008 takes a place with maximum (+ve) value in difference of (1.903) $\mathrm{m}$ to maximum (-ve) value of $(-0.760) \mathrm{m}$ and $(62.2) \mathrm{cm}$ standard deviations. Finally, we have PPP technique with values ranges from $(1.928) \mathrm{m}$ to $(-1.856) \mathrm{m}$ and standard deviations of $(68.35) \mathrm{cm}$ as the most worst results of the used technique.

It should note here according to table (1) results of EGM2008 and PPP techniques, the worst results for these both techniques at points from (R31) to (R38) located along Aqaba Gulf zone area from Sharm ElSheikh city to Taba city through Dahab and Nwibaa cities, due to inaccurate Global Geopotential models along these area may be due to the lack or inaccurate data in these area.

\section{CONCLUSIONS AND RECOMMENDATIONS}

According to the above results and discussion, it is clear that it is possible to obtain orthometric heights using GPS observations using several techniques as shown in this research. These methods give different levels of accuracy after taking into some considerations and constraints regarding observation process and established reference points along the study area.

Creation of local geoid model technique along the study area using krigging method gives the best accuracy comparing with the other techniques. The most important step in this technique is the selection of numbers and locations of established reference points used in modeling according to the required accuracy and geoid surface criteria. The more required accuracy needs, the more number of reference points and the closer these points to each other.
Technique of baseline difference may be used in obtaining orthometric heights especially in areas with a small change in geoid surface and sufficient numbers of known benchmarks. The use of EGM2008 GGMs from the most popular technique in obtaining orthometric height although it's accuracy may be reach to about one meter. Technique of PPP gives the worst results of all other techniques and it is recommended not to be used for obtaining orthometric heights due to its low accuracy along the study area. It should be noted that EGM2008 needs densification of new points at Al Aqaba Gulf to improve its accuracy along this area.

As a results, precise local geoid model creation for all over Egypt zone area should be recommended by co-operation of all interested organizations such as Egyptian Survey Authority, Survey Research Institute, Remote Sensing Organization, and Helwan observatory. This model may replace levelling process with an acceptable accuracy.

\section{REFRENCES}

Balasubramaniam Al-Ghamdi K., and Dawod G. (2013). " Accuracy assessment of global geopotential models for GIS and geomatics applications in Makkah metropolitan area". The Eighth National GIS Symposium in Saudi Arabia, April 2013, pp. 1-13.

Andrew W. Sutter, Alan G. Evans (2004). "Evaluation of Precise, Kinematic GPS Point Positioning". Proceedings of the Institute Of Navigation (ION) GNSS-2004 Meeting, Long Beach, California, USA.

Bisnath, S., Gao, Y. (2009). "Current state of precise point positioning and future prospects and limitations". IAG Symp. Vol.133, pp:615-623.

Dawod, G., Mohamed, H., and Ismail, S. (2010). "Evaluation and adaptation of the EGM2008 geopotential model along the northern Nile valley, Egypt: A case study". Journal of Surveying Engineering, Vol. 136, No. 1, February 2010, pp. 36-40.

El-Shouny A. and Yakoub N. (2015). " Comparative study of different surface fitting methods for geoid modeling along the Rosetta coastal zone area" . Regional Conference on Surveying \& Development , Sharm El-Sheikh, Egypt, 3-6 October 2015.

GA (2011). AUSPOS - Online GPS processing service,

http://www.ga.gov.au/earthmonitoring/geodes y/auspos-online-gps-processing-service.html (accessed Feb 2012). 
Kouba J. (2009). "Guide to Using International GNSS Service (IGS) Products". (Jet Propulsion Lab., Pasadena,; http://igscb.jpl.nasa.gov/components/usage.ht $\mathrm{ml}$.

Luo, X.; Gao, J.; Jin, X.; Li, J., and Chu, F., (2015) - "The latest application to determine tide height in a large-scale sea using shipborne GPS based on precise point positioning and EGM2008". In: Mi, W.; Lee, L.H.; Hirasawa, K., and Li, W. (eds.), Recent Developments on Port and Ocean Engineering. Journal of Coastal Research, Special Issue, No. 73, pp. 319-324. Coconut Creek (Florida), ISSN 0749-0208.

Mohamed H. F. (2015). "Assessment of Factors Influencing Static GNSS Precise Point Positioning: A case study in Egypt". Int. Journal of Applied Sciences and Engineering Research, Vol. 4, Issue 5, 2015.
Qiuying Guo (2015). "Precision comparison and analysis of four online free PPP services in static positioning and tropospheric delay estimation GPS Solution". Vol.19, pp:537-544

Survey Research Institute Technical Report (2016). "Technical Report of the survey work performed along Egyptian coastal zone areas as a part of the project " Establishment and strengthening surveying benchmarks along Egyptian coast". NWRC, (june 2016).

Zumberge, J.F., Heflin, M.B., Jefferson, D.C., et al., (1997). "Precise point positioning for the efficient and robust analysis of GPS data from large networks". J. Geophys. Res. 102 (B3), 5005-5017. 